OPEN ACCESS

Edited by:

Sabine Pirchio,

Sapienza University of Rome, Italy

Reviewed by:

Trung Tran,

Vietnam National University, Vietnam

Chinh Nguyen,

Dong Nai University of Technology,

Vietnam

*Correspondence:

Adam I. Attwood

attwooda@apsu.edu

Specialty section:

This article was submitted to Educational Psychology, a section of the journal

Frontiers in Education

Received: 18 January 2021 Accepted: 15 June 2021 Published: 02 July 2021

Citation:

Attwood Al (2021) An Anecdotal Case Study in Psychological Anthropology

of Two Retired Middle School

Teachers' Perceptions of Classroom

Life in the United States.

Front. Educ. 6:655457.

doi: 10.3389/feduc.2021.655457

\section{An Anecdotal Case Study in Psychological Anthropology of Two Retired Middle School Teachers' Perceptions of Classroom Life in the United States}

\author{
Adam I. Attwood * \\ Department of Teaching and Learning, Austin Peay State University, Clarksville, TN, United States
}

In this qualitative study, interviews of two former middle school teachers were conducted and analyzed for how they fostered a supportive classroom environment in the United States despite the national stress of the Vietnam War during the late 1960s and early 1970s. Half a century later in 2020-2021, similar trends seem to remain just as important in society though the context has shifted. Implications for social-emotional learning from then and now are discussed. Each of the two participants in this study established centralized control through slightly different means and both used written guidelines and rules while emphasizing prosocial behaviors. Three themes emerged: 1) a syllabus was important in management style, 2) sports, and 3) the national social context-such as the Vietnam War-manifested itself in the discourse of the social environment to affect classroom life. Implications for the socio-spatial context of school architectural layout are explored.

Keywords: classroom life, middle school teachers, semi-structured interview, social-emotional development, sociospatial context, psychological anthropology, Vietnam War legacy, coach identity

\section{INTRODUCTION}

This case study provides an answer to the question: What was a perspective of middle school classroom life and management from the Vietnam War era? This question was asked because of the approaching fifty-year anniversary of the end of the Vietnam War. This seemed like a historical moment to get the recollections of former middle school teachers as a snapshot in time and for their implications for middle school classroom life. The interviews that are the focus of this paper are of two former middle school teachers who taught in the late 1960s to early 1970 s.

The purpose of this study was to explore the research question: What changes or continuities in middle school classroom management were there in America from a case study perspective of former in-service middle school teachers? The assumption is that there are generational cultural cycles. This is a qualitative case study in psychological anthropology, what Stein (1985), Rosa (1996) called psychoanthropology. According to Stromberg (2009), psychological anthropologists "are interested in many of the same questions as Psychologists, except that we PAs (psychological anthropologists) always try to think about the possibility that human activity is based not only in personality or the nervous system but also in a person's culture and social environment" (para. 2). Two former middle school teachers who taught between the years 1967-1971 agreed to interview for this study. The semi-structured interviews were transcribed. The difference in time and age is an intentional component of the study because this is a case study comparison (Stake, 1995) between two former 
middle school teachers. Discussion will include the importance of architecture and classroom organization to the social process of teaching and learning.

\section{LITERATURE REVIEW}

The concept of middle school has undergone changes in the late 20th century as "middle school" replaced "junior high school" in many districts in the United States (Tamer, 2012). The language used to describe the middle grades suggests how education is conceptualized (Wortham, 2008). The junior high school tended to be more focused on subject matter content, while the concept of middle school attempts to balance subject matter content with social-emotional development that educational psychologists suggested is important for the age group in grades 6-8 (Roeser et al., 2000).

Managing the middle school classroom was also increasingly viewed as distinct from elementary school and high school in the late 20th century and twenty-first century. While fostering positive relationships between students and teachers has long been established as important at every grade level, the middle school context of early adolescence requires its own strategy of relationship-building. According to Beaty-O'Ferrall et al. (2010): "Teachers who adopt a relationship-building approach to classroom management by focusing on developing the whole person are more likely to help students develop positive, socially-appropriate behaviors" (p. 5). This is not a different process from high school, but it can include a different level of quasi-parental perspective as it is the transitional age group between child and adolescent (Akmal and Larsen, 2004). Related to these observations through a social cognitive lens is the role that the coach identity can have in potentially supporting teacher authority which often seem to be anecdotal, yet influential (Cossentino, 2004; Pope et al. 2014; Dervent and Inan 2015).

Social support in school promotes student retention and graduation across student groups (Demir and Leyendecker, 2018). The middle school sets the stage for students going into high school, so the ways in which middle schools are structured socially and psychologically can either incentivize or disincentivize prosocial and academic development (Beaty-O'Ferrall et al., 2010). Middle school design can facilitate co-regulation skills in students so that the teacher is more a facilitator of learning than behavior manager. As Quackenbush and Bol (2020) concluded in their study of the social dynamic of co-regulation blurring together with social regulation between teacher and students in a middle school mathematics classroom: "In these two cases, the teachers were effectively but implicitly sparking socially-shared regulation of learning among teams of students" (p. 7). Such a process can be seen throughout modern schooling going back at least to the midtwentieth century. This study provides another vantage point of discussion for this concept of social regulation and co-regulation in the middle school classroom.

Each generation has its own context while also having many continuities from previous generations that overlap. The Vietnam War was a time of socio-political change and civil rights marches.
This context affected the students, families, teachers, and administrators in schools across the United States. One of the many effects of the Vietnam War legacy was, in part, its influence on immigration to the United States. For example, English language learning (ELL) began to be implemented more widely and systematically in the 1970s to meet the needs of language learners, especially those who were refugees from the Vietnam War that decade (McCall and Vang, 2012). The increased attention to ELL in American public schools in the 1970s was caused, in part, because of the socio-political changes of the Vietnam War (Nguyen, 2018).

Using the life-history method, Nguyen (2018) interviewed three individuals who were English language learners in Vietnam to explore their perceptions and experiences of school. The Vietnam War influenced perceptions; influencing geopolitics that affected teachers as well as students. According to Nguyen (2018), "Drawing on the narratives of the participants, we can see that this language conveyed political implications specific to the socio-historical milieu of Vietnam during the 1975-1990 period" (p. 624). The Vietnam War had a lasting influence on socio-political contexts of school in both Vietnam and the United States and, thus, is an important reference point in time for the study of schools and educational context. Lessons from those influences are important in the study of change and continuity of school structure.

\section{CONCEPTUAL FRAMEWORK}

This is a case study of two former middle school teachers' perspectives of their time teaching in the United States from 1967 to 1971 . This case study method is based in part on the sociocultural approach of Bartlett and Vavrus (2014) that situates a study across micro-level to macro-level contexts. This type of multidisciplinary approach is what Stromberg (2009) called psychological anthropology. The interview method was informed by Sawyer and Norris (2013) concept of duoethnography in which the two participants are the case study. Semi-structured interviews were used as this gathers primary information for analysis (Briggs, 2007). This study is a combined conceptual framework similar to a prism in that the output is a result of analyzing separate components of the data that are connected yet different in their implication.

This case study addresses an aspect of social-emotional development for the middle school classroom environment as seen through the lens of two retired middle school teachers who taught during a time of social change in the late 1960s and early 1970s. The two teachers in this study addressed social-emotional learning in different ways for social studies and science classes, respectively. The interviews were recorded and transcribed manually. On the qualitative spectrum, this study is part of a hermeneutical understanding of school environments based on a semi-structured interview protocol of individual perception in context of larger social phenomena (e.g., the context of the Vietnam War in the late 1960s and early 1970s) and that the socio-spatial structure of schools affects individual roles (see Appendix). 


\section{RESEARCH DESIGN}

After reading the informed consent statement as approved by this researcher's Institutional Review Board, the two participants were given the semi-structured interview protocol ahead of the interviews (Stake, 1995). The interviews were voice recorded and transcribed by this researcher. The voice recorder was placed on the table in between the researcher and participant after acknowledging that the interview was being recorded for this study in accordance with the informed consent statement. Participants were given their transcribed interviews after completion for them to review. Anonymity was ensured by redacting any personal information in the transcription.

This researcher interviewed the two participants with a voice recorder and then transcribed the recording manually. The transcripts were given to the participants to review before finalizing and to ensure that identifying information was redacted. Themes were derived by this researcher manually without software based on a modified duoethnography model (Sawyer and Norris, 2013). The modification to the Sawyer and Norris (2013) model is that instead of this researcher entering a dialogue with another researcher about the interviews, this researcher entered dialogue with the participants directly to check for thematic agreement (e.g., the importance of the Vietnam War on the social-emotional context of the United States in the late 1960s and early 1970s). The participants reviewed the transcript prior to writing the paper and then read the first draft of the paper prior to submission. As part of the purpose of this study was to explore anecdotal perception of classroom life from recollections of the Vietnam War era in the United States, the effects of the Vietnam War legacy on social-emotional development emerged as a theme. The role of sports in middle grades social-emotional development also emerged during the interviews. Likewise, this researcher was interested in the transition from the junior high school model to the middle school model and what potential insights individuals who were teachers during the late 1960s and 1970s might have that could provide further understanding of this thematic shift in the structure of early adolescent education. As such, this study is a psychological-anthropological case study in anecdotal experience that provides anecdotal insights into middle grades educational continuity and change based on a larger social context.

The transcripts that are analyzed from the two retired middle school teachers' interviews are like narration ready for unpacking to understand what Pinar et al. (1995) suggested were the heretofore hidden "stories that never end, stories in which the listener, the 'narratee,' may become a character or indeed the narrator, in which all structure is provisional, momentary, a collection of twinkling stars in a firmament of flux" (p. 449). In other words, individual narratives are as important as large data sets, though different in how they are used for recommendations for curricular practice. Interview data presents a story that would otherwise go unread.

This study focuses on the interview data as a case study exploring the concept of middle school classroom life from a snapshot in time. This case study being structured on an interview of two former middle school teachers allows for reflection on their teaching practice based on the things that most imprinted on their memories. The individual within the larger school culture emerged as important. The years 1967-1971 are emphasized because of an interest in commemorating the fifty-year anniversary of the end of the Vietnam War. With sociopolitical unrest leading to social change, there are parallels that an anecdotal case study can illuminate for discussion.

\section{FINDINGS AND DISCUSSION}

The findings from each of the two interviews were more different than similar. As a case study using a semi-structured interview protocol, the individual participants determined what they saw as personally important. Although both schools that the participants taught at were urban and during the same time frame, the two schools were on different coasts of the United States, had different population composites, different sizes, different emphasis on sports, and different classroom management styles because of local culture. Three themes emerged: 1) a syllabus was important in management style, 2) sports were important in social cohesion and the absence of sports was seen as a deficit, and 3) the national social context-such as the Vietnam War-manifested itself in the discourse of the classroom environment to affect classroom management practice.

Participant $1-\mathrm{a}$ male social studies teacher-noted that although his mentor teacher during his student teaching practicum was authoritarian, Participant 1 considered himself to be "cooperative" and not "assertively authoritative." He seemed to reference his role as a football coach as one that was more pastoral than authoritarian. Participant 1 noted that this style of management worked because:

(Participant 1) My style was more to be in a partnership with the students-more or less informal and not particularly disciplinarian-but demanding academically. And it worked with my particular students. It would not have worked in many other school atmospheres in my opinion, but it certainly worked in the school I was in and the students I was teaching.

This suggests that because he was of the same culture as the majority, that there was a cultural understanding in which the dominant culture of the area expected a somewhat "informal" approach to discipline. Rules, in other words, did not necessarily need to be written and posted on the wall. This seems to be in keeping with what Caughlan (2005) observed of "pastoral power," as well as what Pope et al. (2014) suggested about the importance of the coach identity as a role of social importance in communities.

Both participants indicated that they provided a syllabus to their seventh-grade students at the beginning of the school year. Participant 1 noted:

(Participant 1) Well, I did have a syllabus. Let me back up a little bit; I certainly had a syllabus, but I didn't have specific 
rules for behavior in the classroom. But I did have a specific syllabus that I handed out at the beginning of the year, the academic period.

Participant 2 (a female science teacher from the east coast) on the other hand indicated that explicitly spelled-out rules were needed-because of experience.

(Interviewer) Did you have written rules and guidelines?

(Participant 2) Not the first year.

(Interviewer) And the second year?

(Participant 2) The second year I did.

(Interviewer) And how did you go about constructing those rules?

(Participant 2) I thought about it over the summer-I mean always had a syllabus, but I think what you're talking about are other expectations.

(Interviewer)Yes.

(Participant 2) What I came to understand my first year is that children that age want rules; they want structure-they want to know what the expectation is. Because, as I said, seventh grade is such an extremely difficult year. My experience in the area where I was, was that students needed and wanted to be told by an adult that they trusted what the expectation was. They did not want to make those decisions for themselves-for the most part. And so, over the summer, when I thought about the challenges I had for the first year, I spent a great deal of time thinking about how I would structure my approach during the second year. So, I did, I had rules-hopefully not too many rules, but just basically what the rules were. You know, about speaking or, you know, what would seem now to be maybe insignificant-but, chewing gum or where you sit or things like that. That was all set out, because I just found that kids that age in that area wanted to know exactly what was expected of them.

Participant 2's experience in her first year of teaching prompted her to change from the relatively informal management style (as outlined by Participant 1) to the more formal management style of rules to be documented in the syllabus like a contract. Participant 2 suggested that implementing the formal rules in her next year of teaching seemed to be an integral part of fostering a stable learning environment. Both participants had protocols, but they manifested differently. Participant 2, the science teacher, began this way in the second year after adapting her management style from what she learned her first year of teaching:

(Participant 2) They came in, I let them sit where they wanted to sit, and told them very specifically to choose carefully because they were not going to be able to change seats at all the whole year. I then made a seating chart and made sure that I memorized the name of every student. I found that is amazing for having a calm class - is to be able to redirect a student by immediately calling them by name, not having to walk over to them or talk to them or anything-simply calling them by name calmly, clearly calmly redirecting conduct.
(Participant 2) Okay, my second year, I felt like I had no disciplinary problems. And, as I said, I think the reason for that was that I made sure I knew every child's name by the second day in class. And so I tried to exude self-confidence and was very clear and directive when I spoke to them. So, I just think that created an atmosphere where the student knew what was expected of him or her-including the fact that I set forth the rules from the start. The first year I thought I did have some discipline problems with the one class that I was warned that I would (laughter), and, I'm not sure that I ever did-I don't think it was until the end of the year that I ever felt that things calmed down in that class at all.

Keeping the seventh-grade classes under control seemed to be a constant process of negotiation. Mediating venues that were attached to the school but not class, such as sports events, seemed to be a part of that negotiation process. Sports-football in particular-seemed to be a means that Participant 1 could use as a mode of amplifying his negotiating authority, because of his status as the assistant coach for what he noted was a "very successful" football program. Participant 1 noted that the authority of a football coach was a special type of authority different from the authority he had as a teacher:

(Participant 1) That's easy because if you're a coach you are the authority. And, you demand discipline. Any athletic endeavor demands discipline. If the individuals don't conform to that discipline then they're benched-they're marginalized. And no student really wants to be marginalized, particularly when they are all out competing for a position on the football team-a successful football team. If the program is successful, if the athletic endeavor is successful, and it garners a lot of positive reaction from parents, students, coaches, the public in general, then it has an inherent discipline all of its own. It's easy to get the kids to cooperate-it's never a problem in a successful athletic endeavor-it's never a problem.

This extra type of authority seemed to amplify his authority as a teacher. Participant 2, however, taught at a school that did not have any after-school sports programs. Perhaps this missing layer of school-sponsored sports removed a potential additional source of authority from teachers. Participant 1 suggested that motivation was the key factor surrounding sports and that the motivation within sports could be complimentary to motivating academic performance.

Individual students seemed to respect Participant 1's authority as the football coach and teacher combined. The combination of roles as football coach and teacher reinforced each other to augment the teacher's classroom authority. This seems to support Dervent and Inan (2015) social cognitive theory of football coaches' influence on student-athletes' academic success and social development through the concept of social role modeling. The coach identity can be an important component of a teacher's management effectiveness inside and outside the classroom (Pope et al., 2014). Similarly, Cossentino (2004) noted that the coach identity can be an important way for teachers to reinforce their pedagogical authority. 
Participant 1 indicated that his football team was considered successful and that some of the players were also students in his classes. Classroom management overlapped with football field management and the combination seemed to be an effective means of generating self-contained respect in which students respected him as a teacher-coach without needing any assistance from administration. In other words, Participant 1 was a nearly self-contained figure of authority from the beginning.

(Interviewer) How often did you have to involve administration in disciplinary issues?

(Participant 1) Very rarely; I rarely bothered them. The students were full of energy, but they were never hostile. So, and they were never really hostile toward each other either. They were just full of energy or they were emotional over something-could be a positive emotion, could be a negative one-but there was no real friction on a personal ad hominem level, detectable by myself. And if there ever was ever anything like that, particularly with the 11th graders, if they were interested in football, I would resolve it on the football field. ... Everybody would have a laugh. It was never hostile. I was never assertively authoritative-I didn't try to heavily assert my authority. I would just say that it's time for you to calm down and it's time to cooperate.

This further suggests Participant 1's authority as both coach and teacher in effectively maintaining a goal-oriented management approach for social studies similar to the goal-oriented approach in football discussed by Dervent and Inan (2015). His identity as football coach and teacher created additional strategies for maintaining authority in which the football field was a second classroom. The two fields-classroom and football-reinforced the teacher's authority. This was done in what Jansen and Kiefer (2020) discussed as a social-emotional development approach relevant to middle school students to meet them where they are and to encourage prosocial skills within school environments that include the classroom and the sports field.

Participant 2, the female science teacher, although in a different context from the male social studies teacher, also exuded a sense of selfcontained authority who very rarely needed administrator assistance with discipline. Without an identity of a sports coach, she seemed to rely more on the structure of written and spoken rules at the beginning and on the basis of scientific process. Even without the additional identity of sports coach, Participant 2 seemed to utilize the subject-science-as a way to establish a method for students to follow. Every student had an assigned seat, for example, and so that established a set routine that they could follow the entire year. They had set times for lecture, discussion, and interactive laboratory work. Again, a methodological structure was established by Participant 2 so that students "knew what was expected of him or her-including the fact that I set forth the rules from the start" (Participant 2 interview note).

National-level political and social movements seemed to affect teacher practice on a nearly continual basis. The school was not isolated from larger political and social situations. Both participants spoke of their experience teaching during what became known as the height of the Vietnam War. Both participants mentioned the Vietnam War throughout their interview as it related to classroom topics and behavior. Sometimes, the conflict in Vietnam would be discussed in class, especially if Participant 1 thought students were distracted:

(Participant 1) So, I tried to gauge: What was on the minds of these students today? Was it a headline about something in Civil Rights, a headline about the [Vietnam] War? Or some other headline that dominated television or their parents' conversation? And try to relate that to the subject matter during that classroom time. On the other hand, if it was something that had happened at school that they didn't like or that they were puzzled over or that it was concerning to them, then we would talk about it-we would just stop the academic side of class for $10 \mathrm{~min}$ and I'd just let them talk. Then I would bring it back and I tried never to take a position on those things and explain it as best I could.

This was a management tactic to redirect potentially disruptive behavior into a productive activity within the context of the course. In other words, this teacher did not blame the student for being distracted. Instead, the social dynamics of society were acknowledged and allowed to be discussed within the learning environment. This acknowledgment validated students as stakeholders in their own education.

Participant 2, who was teaching on a military base, suggested an even more pronounced affect that the conflict in Vietnam had on student-and teacher-behavior. One of the main affects seemed to be a feeling of uncertainty in which the concept of home moved:

(Participant 2) This was a large urban school. It was on a very large military installation. So to that extent it was probably different from many other large urban schools, and because it was during the height of the Vietnam War people were constantly moving. The teachers moved in and out, the students were moving in and out. And more to the point, I think that the students had more challenges than students at other schools, because most of those students had a father who was absent fighting in the Vietnam War, and had a mother who was working and trying to keep things together at home.

To compensate for the uncertainty, Participant 2 indicated that having delineated rules and expectations on a syllabus and through repetition of example fostered a sense of calm. Participant 2 had a seating chart where each student was assigned a seat for the whole year. This seemed to be a tactic for (re)establishing a sense of home or stability-in a subtle but identifiable way-so that students would come to school knowing that they could always go to the same seat in the same classroom with the same teacher and have a sense of affirming structure. Establishing routine through structured social protocols was important because of relatively low parent involvement.

(Interviewer) Were there any specific curricular guidelines given to you? 
(Participant 2) We were given the books that we were supposed to use. And I had two books to use-one book to be used for, as I say, the more gifted students. And a different book for those who were more challenged. We were told what we were supposed to cover. The type of curriculum it was is there were reading assignments-I would give homework assignments-and we would have discussions, lectures and discussion. And because it was a science class, I also would have a lab. Because money was so tight in this particular area, in fact, I bought a lot of my own supplies for the labs. If I wanted to do particular labs, the school often times didn't have the materials and so I purchased them myself. (pause) Very different from the tax base that we have now for some of our K-12 schools, and (State redacted) was very different from (State redacted). (State redacted) had much more of a focus on the tax base for schools; in (State redacted) that just wasn't the case, at that time.

Money was a much more pronounced issue for Participant 2 than Participant 1 because the local school district in Participant 2 's areas was economically depressed.

(Interviewer) Were you an advisor for any extracurricular activities?

(Participant 2) No, and the reason for that is that these kids did not have a parent who could pick them up after school. So, there virtually were no after-school activities. They either got on the bus or if they were lucky enough to have a parent who could pick them up they could. But, there was no ability to keep a child after school either voluntarily or involuntarily. So, anything that needed to be done in terms of communicating with a child or parent needed to be done during the structured school day.

External financial constraints and the Vietnam War draft was a major cause for parent detachment from their children's school. Parent support is important for student success. If parent support is missing, then it is up to school staff to step in as a local quasi-parent (Akmal and Larsen, 2004). This seemed to be the case during the Vietnam War era, too, as suggested in this interview. Parent support did not seem to be a problem for Participant 1 on the west coast. The contrast is particularly remarkable as well because Participant 2's school did not have after-school sports.

In the context of the late 1960s and 1970s, the United States middle grades system was largely organized into what where called "junior high schools." Starting in the late 1980s junior high schools started to be reorganized into middle schools. Some districts still retained the junior high school model into the 2010s. The junior high school tended to be grades 7-8 while middle schools tended to be grades $6-8$. Sometimes, a junior high school was grades 7-9 in which case the high school included only grades 10-12 and called a senior high school (Tamer, 2012). These organizational shifts to the middle grades structure are important because of their reflection of the changing understandings regarding developmental psychology and educational psychology.

As much as the changes were psychological, they were also linguistic for cultural appeal. The term middle school infers something different than junior high school. As Tamer (2012) suggested, middle school infers a more student-centered approach while junior high school suggests a more contentdriven approach. While a generalization, it does frame the context for why the change in structure of grades 6-8 shifted. While psychological, the labels were also sociocultural and affected the way that middle grades education was conceptualized and taught. Even the design of the school buildings changed so that the architecture reflected the apparent shift in focus of the middle school in comparison to the junior high school.

The language used to describe the middle grades is important because the language use can be what Wortham (2008) called "social action in practice." Here is where the transition from educational psychology to educational anthropology takes place-it is in the social practice of teaching and learning in the middle grades where student social development is as important as their academic development. These concepts are present in the background of interviews with middle school teachers who must consider many different variables of curriculum design and implementation within the changing social context of early adolescent learners in the middle grades.

The physical design of the learning space affects classroom management practice. Social action in practice for management and organization of schools also took the form of changes in the physical design of middle schools. The architecture and layout of a school suggests the priorities and function of the teaching and learning space. Among the spectrum of school designs, there is variation from the traditional segmented, rigidly separate rooms with disciplinary boundaries to the open concept plans that foster interdisciplinary collaboration. Floorplans and architectural design can influence social cognitive process, according to Dovey and Fisher (2014).

While classroom management in the middle grades has often been analyzed from psychological perspectives, there is much to be learned from anthropological research methods in conjunction with the psychological study of the middle school environment (Jansen and Kiefer, 2020). The shift in focus from the junior high school model to the middle school model can be inferred in the physical design of the school buildings. The physical redesigns that began to emerge in the late 1970s infer the curriculum reforms. The junior high school layout tended to emphasize content-focused instruction.

The middle school layout tended to emphasize the concept of student-centered instruction. The hybrid instructional format would become more common in which there is a balance between these two models. With the blending of content-focused and student-centered instruction came the blending of the physical layout of the school building itself. The architecture was partially a reflection of the instructional type. The student-centered or hybrid models tended to reflect what Dovey and Fisher (2014) discussed as the renewed interest in the role of socio-spatial variables in teaching and learning. 


\section{CONCLUSION}

The two interviews analyzed in this qualitative study suggest that each of the two former middle school teachers interviewed fostered an inclusive and supportive classroom environment in different ways depending on their local school social context. The importance of national social trends (e.g., politics in the Vietnam War), classroom structuring from the start of the year (e.g., syllabus and classroom rules), and the importance of the coach identity manifested differently. These seem to be common themes across classrooms and time, anecdotally substantiating studies by Pope et al. (2014) and Dervent and Inan (2015) on the coach identity in which they concluded that such an identity can augment the teacher's authority because of social modeling in social cognitive theory in which students look up to a coach as a role model or figure of authority. Each of the two participants in this study established centralized control through slightly different means and both used written guidelines and rules. But the reliance on written rules varied based on each teacher's assessment of the social-emotional development of their students at that time and within the larger community context.

The divergence in the two participants' experiences with sports was perhaps the largest contrast. The social studies teacher was also the assistant football coach, and this added to his authority. The science teacher was at a school where parent involvement was relatively low because of external financial and work constraints coupled with the school not having sports programs. There was a code of conduct, but that code seemed

\section{REFERENCES}

Akmal, T. T., and Larsen, D. E. (2004). Keeping History from Repeating Itself: Involving Parents about Retention Decisions to Support Student Achievement. RMLE Online 27 (2), 1-14. doi:10.1080/ 19404476.2004.11658171

Bartlett, L., and Vavrus, F. (2014). Transversing the Vertical Case Study: A Methodological Approach to Studies of Educational Policy as Practice. Anthropol. Educ. Q. 45 (2), 131-147. doi:10.1111/aeq.12055

Beaty-O'Ferrall, M. E., Green, A., and Hanna, F. (2010). Classroom Management Strategies for Difficult Students: Promoting Change through Relationships. Middle Sch. J. 41 (4), 4-11. doi:10.1080/ 00940771.2010 .11461726

Briggs, C. L. (2007). Anthropology, Interviewing, and Communicability in Contemporary Society. Curr. Anthropol. 48 (4), 551-580. doi:10.1086/518300

Caughlan, S. (2005). Considering Pastoral Power: A Commentary on Aaron Schutz's "Rethinking Domination and Resistance: Challenging Postmodernism". Educ. Res. 34 (2), 14-16. doi:10.3102/ 0013189X034002014

Cossentino, J. (2004). Becoming a Coach: Reform, Identity, and the Pedagogy of Negation. Teach. Teach. Theor. Pract. 10 (5), 463-487. doi:10.1080/ 1354060042000243033

Demir, M., and Leyendecker, B. (2018). School-related Social Support Is Associated with School Engagement, Self-Competence and Health-Related Quality of Life (HRQoL) in Turkish Immigrant Students. Front. Educ. 3 (83), 1-10. doi:10.3389/feduc.2018.00083

Dervent, F., and İnan, M. (2015). Metaphorical Conceptualizations of Football Coach through Social Cognitive Theory. J. Educ. Train. Stud. 3 (4), 158-168. doi:10.11114/jets.v3i4.826 to be based mostly on unwritten principles of respect and conventions of interpersonal conduct through personality, constructs of protection or safety (such as defending each other for team cohesion on and off the field), and the negotiation between individual and team in which the individual has more freedom up to the point where that freedom intersects the team goal.

\section{DATA AVAILABILITY STATEMENT}

The interview data from this study is quoted in this article. The raw interview data may be made available upon request. Identifying information is redacted in accordance with the approved research protocol.

\section{ETHICS STATEMENT}

This study involving human participants was reviewed and approved by the Austin Peay State University Institutional Review Board. The participants provided their written informed consent to participate in this study.

\section{AUTHOR CONTRIBUTIONS}

The author confirms being the sole contributor of this work and has approved it for publication.

Dovey, K., and Fisher, K. (2014). Designing for Adaptation: The School as SocioSpatial Assemblage. The J. Architecture 19 (1), 43-63. doi:10.1080/ 13602365.2014.882376

Jansen, K., and Kiefer, S. M. (2020). Understanding Brain Development: Investing in Young Adolescents' Cognitive and Social-Emotional Development. Middle Sch. J. 51 (4), 18-25. doi:10.1080/00940771.2020.1787749

McCall, A. L., and Vang, B. (2012). Preparing Preservice Teachers to Meet the Needs of Hmong Refugee Students. Multicultural Perspect. 14 (1), 32-37. doi:10.1080/15210960.2012.646847

Nguyen, C. D. (2018). Localised Politics in Language Education: Untold Stories Hist. Educ. 47 (5), 611-627. doi:10.1080/0046760X.2018.1432076

Pinar, W. F., Reynolds, W. M., Slattery, P., and Taubman, P. M. (1995). Understanding Curriculum: An Introduction to the Study of Historical and Contemporary Curriculum Discourses. New York, NY: Peter Lang.

Pope, J. P., Hall, C. R., and Tobin, D. (2014). How Do Coaches Identify with Their Role as a Coach? Exploring Coach Identity through a Role Identity Theory Lens. Identity 14 (2), 136-152. doi:10.1080/15283488.2014.897951

Quackenbush, M., and Bol, L. (2020). Teacher Support of Co- and Socially-Shared Regulation of Learning in Middle School Mathematics Classrooms. Front. Educ. 5 (580543), 1-8. doi:10.3389/feduc.2020.580543

Roeser, R. W., Eccles, J. S., and Sameroff, A. J. (2000). School as a Context of Early Adolescents' Academic and Social-Emotional Development: A Summary of Research Findings. Elem. Sch. J. 100 (5), 443-471. doi:10.1086/499650

Rosa, A. (1996). Bartlett's Psycho-Anthropological Project. Cult. Psychol. 2 (4), 355-378. doi:10.1177/1354067X9600200401

Sawyer, R. D., and Norris, J. (2013). Duoethnography: Understanding Qualitative Research. New York, NY: Oxford University Press.

Stake, R. E. (1995). The Art of Case Study Research. Sage. 
Stein, H. F. (1985). The Psychoanthropology of American Culture. New York, NY: The Psychohistory Press.

Stromberg, P. G. (2009). What Is Psychological Anthropology? Psychology Today. Available At: https://www.psychologytoday.com/us/blog/sex-drugs-and-boredom/ 200909/what-is-psychological-anthropology (Accessed October 1, 2020).

Tamer, M. (2012). Do middle Schools Make Sense? Harvard Ed. Magazine. Available At: https://www.gse.harvard.edu/news/ed/12/09/do-middle-schoolsmake-sense (Accessed October 1, 2020).

Wortham, S. (2008). Linguistic Anthropology of Education. Annu. Rev. Anthropol. 37, 37-51. doi:10.1146/annurev.anthro.36.081406.094401
Conflict of Interest: The author declares that the research was conducted in the absence of any commercial or financial relationships that could be construed as a potential conflict of interest.

Copyright $(2021$ Attwood. This is an open-access article distributed under the terms of the Creative Commons Attribution License (CC BY). The use, distribution or reproduction in other forums is permitted, provided the original author(s) and the copyright owner(s) are credited and that the original publication in this journal is cited, in accordance with accepted academic practice. No use, distribution or reproduction is permitted which does not comply with these terms. 


\section{APPENDIX}

\section{Semi-Structured Interview Protocol}

To Participant (“interviewee," also addressed as “you” or “your”):

This interview is intended for former school teachers and in-service teachers. You have been asked to participate in this study because of your status as a former or current school teacher (including any grade level in K-12). Interviews will be voice recorded and transcribed. Results will be published in the researcher's dissertation and potentially other scholarly venues, including but not limited to scholarly journals and books. Any personally identifiable information from the participants (interviewees) will be redacted for publication to maintain interviewee anonymity. You may stop your interview at any time. Your transcribed interview is available upon request from the researcher conducting the interview.

The purpose of this interview is to add to the field of educational research on school and classroom life and management. The questions in this survey are designed to specifically 1) identify the manners that characterized classrooms and schools by 2) saving your first-person account of your experience as a K-12 teacher.

The researcher (interviewer) will publish in whole or in part your interview (with any personally identifiable information redacted) and will analyze your interview and other participants' interviews with the purpose of adding to the literature on classroom life and management and any other applicable fields of educational research. Interview questions:

1. What grade levels did you teach? What year(s) did you teach? How would you generally describe the school-urban or rural, et cetera?

2. How would you characterize students' manners in your school?

a. Did you have a specific idea of your classroom management plan at the beginning of the school year?

b. What was your philosophy of authority and management in the classroom? In extracurricular activities?

i. Did you try to instill specific manners in your classroom management plan?

ii. How would you characterize the ways in which students interacted with each other in your classroom?

iii. Were there significant differences between genders in their manners?

c. How would you characterize teachers' manners in your school? 